\title{
Mutual Relationship Between Upper Extremity Function and Core Muscle Endurance in Patients with Multiple Sclerosis
}

\author{
Cagla Ozkul ${ }^{1}$ (D), Arzu Guclu Gunduz ${ }^{1}$ (D), Murat Esmer ${ }^{1}$ (D), Muhammed Seref Yildirim ${ }^{1}$ (iD, Kader Eldemir $^{1}$ (D), Ceyla Irkec ${ }^{2}$ (D) \\ ${ }^{1}$ Gazi University, Faculty of Health Sciences, Department of Physiotherapy and Rehabilitation, Ankara, Turkey. \\ ${ }^{2}$ Gazi University, Faculty of Medicine, Department of Neurology, Ankara, Turkey.
}

Correspondence Author: Cagla Ozkul

E-mail: caglaozkul@hotmail.com,caglaozkul@gazi.edu.tr

Received: $13.10 .2020 \quad$ Accepted: 11.01 .2021

\begin{abstract}
Objective: This study aimed to determine the relationship between upper extremity function and core muscle endurance in patients with multiple sclerosis (PwMS).

Methods: Twenty-two PwMS and 20 healthy controls (HC) were included in this retrospective cross-sectional study. The upper extremity function was assessed by the Nine Hole Peg Test (NHPT). In addition, the core muscle endurance was assessed by the side bridge test, trunk flexor endurance test, trunk extensor test, and prone bridge test.

Results: Upper extremity function and core muscle endurance (except extensor endurance) in PwMS were lower compared to HC ( $\mathrm{p}<0.05$ ). In addition, the results of correlation analyses in PwMS showed that both sides' upper extremity functions were related to EDSS, and trunk flexor endurance $(p<0.05)$. Moreover, the right-upper extremity function was related to the right side bridge endurance test performance while the left-upper extremity function was related to left side bridge endurance test performance and disease duration ( $p<0.05$ ).

Conclusion: These results demonstrated the mutual relationship between upper extremity function and core muscle endurance in PwMS. Therefore, the core stabilization training may improve both the core muscle endurance and upper extremity function in PwMS.

Keywords: Multiple sclerosis, upper extremity, core muscle, endurance.
\end{abstract}

\section{INTRODUCTION}

Motor and sensory dysfunctions occur in patients with multiple sclerosis (PwMS) due to central nervous system damage. The cohort study of the North American Research Committee on Multiple Sclerosis (NARCOMS), containing data from 23931 PwMS, yielded that upper extremity dysfunction was reported by $60 \%$ of patients in the first years of the disease, and in $86 \%$ of patients in the 30th year of the disease (1). Moreover, over time, not only prevalence but also the severity of dysfunction increase in PwMS. Upper extremity dysfunction causes declines in cognitive functions, quality of life, and abilities in activities of daily living (ADLs) in PwMS (2).

Movements of the upper extremity require proximal stabilization during manipulative and targeted activities. Therefore, the prerequisite for upper extremity functions is to provide trunk stabilization (3). The upper extremity moves through trunk stabilization, power generation, and power transfer which are supported by activation of the core muscles (4). That is, core stabilization is required to generate and transmit forces along the kinetic chain between the upper extremity and core region $(5,6)$. Abdominal muscles co-contract with lumbar extensor muscles to increase the stability of the spine during and before activity $(7,8)$. Therefore, core stability created by the activation of core muscles is important and essential for many upper extremity activities (9).

It has been demonstrated that there is a positive relationship between upper extremity functions and postural control in children, older people, and Parkinson's patients (10-12). In addition, impaired upper extremity function was also found to be associated with decreased postural control in PwMS, even mild disabilities (13). However, the relationship between core muscles involved in postural control and upper extremity function is not yet known. Defining this relationship may contribute to the development of rehabilitation approaches aimed at improving upper extremity function in PwMS.

Therefore, the aim of this study is to determine the relationship between upper extremity function and core muscle endurance in PwMS. 


\section{METHODS}

\subsection{Participants}

PwMS and healthy controls (HC) were included in this retrospective cross-sectional study which was conducted at Gazi University, Department of Physiotherapy and Rehabilitation from 2018 to January 2020. The study protocol was approved by the Gazi University Ethics Commission (No:518). The patients were recruited by their neurologists who gave the diagnosis according to McDonald criteria (14) and determined the Expanded Disability Status Scale (EDSS) score (15). The McDonald criteria are consist of a combination of clinical tests, magnetic resonance imaging, cerebrospinal fluid, and evoked potentials and regarded as the gold standard for the standard diagnosis of MS (14). The EDSS is the most common clinical scale that measures the disability of MS patients (15). The scores of EDSS range from 0 (normal) to 10 (death due to MS) based on eight functional systems consisting of pyramidal function, cerebellar function, brainstem function, sensory function, bowel/bladder function, mental function, and visual function. For PwMS, the inclusion criteria were (1) the diagnosis of definite MS, (2) age between $18-65$ years (3) ambulatory without aids (EDSS score<6) (15), (4) relapse-free for the last 3 months. Exclusion criteria for all participants were (1) history of neurological disease (other than MS for the patient group), (2) presence of orthopedic, vision, or hearing problems, (3) presence of low back pain, (4) having a history of spinal, or abdominal surgery.

\subsection{Study Design}

The demographic information (age, gender, body mass index) of all participants and disease characteristics (disease duration, the number of relapses, and EDSS) of the PwMS were recorded.

\subsection{Measurements}

First, the assessor explained and showed each test to the participants, then asked the participants to practice the test once. After one practice trial, the participants performed the actual test once. The participants rested for at least 5 minutes between each test. In all assessments, the actual test duration was recorded in seconds by using a stopwatch.

The upper extremity function was assessed by nine-hole peg test (NHPT). All participants were assessed by using the same materials (chair, table, a wooden board with 9 holes, and 9 pegs). The participants sat on a chair and then they picked up nine pegs one at a time as quickly as possible, put them in nine holes, and then removed them again as quickly as possible one at a time $(16,17)$.

Core muscle endurance was assessed by the side bridge test, trunk flexor endurance test, trunk extensor test, and prone bridge test $(18,19)$. Only the trunk extensor test was performed on a bed, other endurance tests were performed on the mat, and these materials were standard in all participants.

2.3.1. Side bridge test: The participants lay on their left / right sides with support from the forearm with elbows below the shoulders and extended their legs straight. Then the participants lifted their hip from the floor. The test was terminated when the side bridge position deteriorated or the hip fell (20).

2.3.2.The trunk flexor test: The participants were in a sit-up position while their trunks were supported at the angle of 60 degrees from the floor. They flexed knees and hips at 90 degrees and crossed arms over the chest. Then, the support of the trunk was removed, and the participants maintained this position as long as possible (20).

2.3.3. Prone bridge test: The participants placed elbows and forearms below their shoulders, straightened the legs. Next, they kept their forearms and toes on the floor, lifted hips, and maintained this straight position as long as possible (18).

2.3.4.The trunk extensor test: The participants lied down on a treatment table, aligning their anterior superior iliac spine with the edge of the table, which allowed the upper body to be planked out over the edge. An assessor fixed the participants' pelvis, hip, and knees to the treatment table. The body and the upper extremities were supported using a chair. Next, the chair was removed, and the participants maintained the horizontal body position as long as possible with their arms crossed position on the chest (20).

\subsection{Statistical Analysis}

Statistical analysis was performed by using the IBM Statistics SPSS v21.0. (IBM Corp. Armonk. NY. the USA). The variables were determined by the measurement (histograms, ShapiroWilk test) and expressed as the median and Interquartile Range (IQR) due to non-normal distribution. Categorical variables were expressed as a percentage. A Mann-Whitney $\mathrm{U}$ test was used to compare PwMS and HC. A Spearman correlation coefficient was performed to determine the relationship between upper extremity function, demographic characteristics, and core muscle endurance. The correlation coefficient was classified as negligible (0-0.10), weak (0.10$0.39)$, moderate (0.40-0.69), strong (0.70-0.89), and very strong (0.90-1.00). The statistical significance level was $\mathrm{p}<0.05$ for all tests (21).

\section{RESULTS}

A total of $22 \mathrm{PwMS}$ and $20 \mathrm{HC}$ were included in this study. The PWMS had mild disabilities [EDSS: median 1.75 (IQR:1.003.63)], and all of them were the relapsing-remitting clinical course of MS. Also, all participants used their right hands dominantly.

Table 1 shows the demographic characteristics, upper extremity function, and core muscle endurance in PWMS and HC. There was no difference between demographic 
characteristics in PwMS and HC. As expected, PwMS were able to finish the NHPT in a longer time than HC $(p<0.05)$. In addition, all core muscle endurance, except trunk extensor endurance were lower in PwMS compared to $\mathrm{HC}(\mathrm{p}<0.05)$.

[Table 1 near here].

Table 1. Demographic characteristics, upper extremity function, and core muscle endurance in PWMS and HC

\begin{tabular}{|c|c|c|c|}
\hline & PwMS (n:22) & HC (n:20) & $\mathbf{p}$ \\
\hline \multicolumn{4}{|c|}{ Demographic characteristics } \\
\hline Age (years) & $34(27.50-46.00)$ & $32.50(23.25-43.75)$ & 0.553 \\
\hline BMI (kg/m2) & $23.64(20.86-25.98)$ & $22.68(19.84-26.21)$ & 0.580 \\
\hline Gender (f/m) (\%) & $16 / 6(72.70 / 27.30)$ & $15 / 5(75 / 25)$ & 0.867 \\
\hline $\begin{array}{l}\text { Disease duration } \\
\text { (years) }\end{array}$ & $6(3.00-11.25)$ & & \\
\hline $\begin{array}{l}\text { Number of } \\
\text { relapses }\end{array}$ & $2.50(1.75-3.25)$ & & \\
\hline EDSS (score) & $1.75(1.00-3.63)$ & & \\
\hline \multicolumn{4}{|l|}{$\begin{array}{l}\text { Upper extremity } \\
\text { function }\end{array}$} \\
\hline $\begin{array}{l}\text { NHPT-right } \\
\text { (seconds) }\end{array}$ & $18.01(15.99-21.34)$ & 15.83 (15.04-16.77) & $0.004^{*}$ \\
\hline $\begin{array}{l}\text { NHPT-left } \\
\text { (seconds) }\end{array}$ & $21.39(17.73-27.76)$ & $17.42(15.09-18.06)$ & $<0.001 *$ \\
\hline \multicolumn{4}{|l|}{$\begin{array}{l}\text { Core muscle } \\
\text { endurance }\end{array}$} \\
\hline Side bridge-Right & $21.11(10.66-37.06)$ & 38.95 (30.66-55.73) & $0.001 *$ \\
\hline Side bridge - Left & $14.54(7.71-26.18)$ & $33.75(22.73-58.88)$ & $0.001 *$ \\
\hline $\begin{array}{l}\text { Extansion } \\
\text { endurance }\end{array}$ & $61.75(36.43-76.97)$ & 60.59 (49.63-87.51) & 0.650 \\
\hline Flexion endurance & $30(19.93-52.62175)$ & 48.26 (32.40-79.59) & $0.009 *$ \\
\hline Prone bridge & $27.68(20.55-46.64)$ & 49.15 (39.21-68.44) & $0.001 *$ \\
\hline
\end{tabular}

Data are presented as number (\%) of patients or median (IQR). ${ }^{*} p<0.05$. chisquare test or Mann-Whitney $U$ test (between two groups). BMI: Body mass index, EDSS: Expanded Disability Status Scale, NHPT: Nine-Hole Peg Test.

Table 2 shows the relationship of upper extremity function with demographic characteristics and core muscle endurance in PwMS. The correlation analysis in PwMS revealed that both sides' upper extremity functions were strongly and negatively related to EDSS, and these were moderately and positively related to trunk flexor endurance $(p<0.05)$. Moreover, the right-upper extremity function was moderately and positively related to the right side bridge endurance test performance while the left-upper extremity function was moderately and positively related to left side bridge endurance test performance $(p<0.05)$. Also, the left-upper extremity function was moderately and negatively related to disease duration $(p<0.05)$.

[Table 2 near here].

Table 2. Relationship of upper extremity function with demographic characteristics and core muscle endurance in PWMS

\begin{tabular}{|c|c|c|c|c|}
\hline & \multicolumn{2}{|c|}{ NHPT-Right } & \multicolumn{2}{|c|}{ NHPT-Left } \\
\hline & $r$ & p & $r$ & $\mathrm{p}$ \\
\hline \multicolumn{5}{|c|}{ Demographic characteristics } \\
\hline Age & 0.111 & 0.623 & 0.228 & 0.309 \\
\hline BMI & -0.048 & 0.832 & -0.084 & 0.710 \\
\hline Disease duration & 0.387 & 0.075 & 0.503 & $0.017^{*}$ \\
\hline Number of relapses & 0.261 & 0.240 & 0.372 & 0.089 \\
\hline EDSS & 0.714 & $<0.001 *$ & 0.765 & $<0.001^{*}$ \\
\hline \multicolumn{5}{|l|}{ Core muscle endurance } \\
\hline Side bridge-Right & -0.446 & $0.038^{*}$ & -0.321 & 0.145 \\
\hline Side bridge - Left & -0.401 & 0.064 & -0.434 & 0.043* \\
\hline Extansion endurance & -0.391 & 0.072 & -0.348 & 0.112 \\
\hline Flexion endurance & -0.504 & $0.017^{*}$ & -0.499 & $0.018^{*}$ \\
\hline Prone bridge & -0.135 & 0.549 & -0.047 & 0.836 \\
\hline
\end{tabular}

${ }^{*} p<0.05$, Spearman correlation test. BMI: Body mass index. EDSS: Expanded Disability Status Scale, NHPT: Nine-Hole Peg Test.

\section{DISCUSSION}

This study investigated the relationship between upper extremity function and core muscle endurance in PwMS. Even though the PwMS in this study had mild disabilities, upper extremity function and core muscle endurance, excluding extensor endurance, were lower than those of $\mathrm{HC}$. In addition, both sides' upper extremity functions of PwMS were related to EDSS. Similarly, Yozbatiran et al. found a relationship between upper extremity functions and EDSS (2). EDSS is the most widely used scale in clinical practice to assess the severity and progression of MS disease (15). However, EDSS focuses much on walking ability rather than upper extremity functions. Therefore, the National Multiple Sclerosis Society's Advisory Committee on Clinical Trials of New Agents in Multiple Sclerosis developed Multiple Sclerosis Functional Composite (MSFC) to overcome the shortcomings of EDSS (22). In this composite, upper extremity functions are also assessed by NHPT as well as the walking ability and cognitive functions. It was reported in a review on upper extremity measures applied in PWMS that the NHPT was the most frequent measure, utilized in $63 \%$ of published studies (23). Also, inter-rater and test-retest reliability of the NHPT are consistently high (range, $r=0.86-0.98$ ) (16).

Bertoni et al. reported that $75 \%$ of PwMS had bilaterally dysfunctions in upper extremities evaluated by NHPT, and participation level reduced $35 \%$ during home activities even in PwMS with mild disability (24). Similarly, in this study, although the PwMS had mild disabilities (median EDSS:1.75), they finished the NHPT in a longer time than HC. Therefore, the upper extremity functions should be evaluated and improved even in PwMS with mild disabilities. 
Moreover, it is known that core muscle endurance is important for balance, functional mobility, coordinated movement, and postural control (25). This study showed that PwMS had lower core muscle endurance, excluding extensor endurance, compared to HC. Similarly, Freund et al. demonstrated that PwMS had lower trunk flexor endurance compared to HC and the lower trunk flexor endurance in PwMS was also associated with lower postural control (26). This relationship is expected since the postural control is provided by core stability, in which the activation of core muscles plays an important role (4). Concerning postural control, Cetisli et al. revealed that lower trunk control assessed by the Trunk Control Test and Trunk Impairment Scale was related to impaired upper extremity function assessed by NHPT in PwMS (13). In line with the result of the study by Cetisli et al., this study presented that both sides' upper extremity functions were positively related to trunk flexor endurance, and also, each upper extremity was positively related to bilateral core muscle endurance in PwMS.

To our knowledge, this study is the first to investigate the relationship between upper extremity function and core muscle endurance in PwMS. The results of this study showed that there is a mutual relationship between upper extremity function and core muscle endurance in PWMS. In elite athletes, a relationship was found between the shoulder internal rotation and external rotation peak torque/ body weight and all core endurance tests except extension endurance tests (27). In addition, Lehman et al. showed that the transversus abdominus muscle and multifidus contracted 50 milliseconds before shoulder movements to provide trunk stabilization in healthy people (28). This evidence suggests that core-based exercises may be effective in increasing upper extremity functions.

Saeterbakken et al. demonstrated that a 6-week core stabilization training increased the maximal ball throwing speed in female handball players (29) while Misirlioglu et al. demonstrated that both sides' shoulder strength increased significantly after a 6-week core stabilization home-based exercise program (30). Moreover, Miyake et al. investigated the effect of one session of core stabilization training on upper extremity function in healthy people (31). At the end of only one session of core stabilization training including three core exercises (curl-up, side bridge, bird dog) for about $20 \mathrm{~min}$, the upper extremity function was higher in the core exercise group than the control group.

Although the effects of core stabilization on upper extremity function have not been investigated yet in PwMS, Bulguroglu et al. showed that an 8-week core stabilization based Pilates training increased core endurance in PwMS (32). Furthermore, in the study by Freeman et al., 5 of 8 PwMS reported an improvement in upper extremity function (rating of carrying a drink while walking by visual analog scale) after an 8-week core stabilization training (33). These results promise that a core stabilization training program may improve both the core muscle endurance and upper extremity function. Future studies are needed to arrive at conclusive evidence on this issue.

This study has several limitations. First, all of the PwMS in this study had a mild disability and relapsing-remitting clinical course of MS. Therefore, our results may not reflect the performance of patients who have a severe disability and other types of MS. Second, the sample size was small, so the power of this study is low. Third, the upper extremity function was evaluated with NHPT, which reflects more manual dexterity rather than proximal upper extremity function. Fourth, the cognitive status of the participants was not taken into account in the inclusion criteria of the study. Lastly, although the endurance of the core muscles was evaluated, the results could not be supported by the evidence on muscle thickness and muscle activation using assessment methods such as ultrasound and electromyography.

\section{CONCLUSION}

This study demonstrated that upper extremity function and core muscle endurance were lower even in PwMS with mild disabilities compared to $\mathrm{HC}$, and mutual relationship between upper extremity function and core muscle endurance in PwMS. Therefore, the rehabilitation program including core stabilization exercises may be beneficial to improve both core muscle endurance and upper extremity function in PwMS. In addition, in future studies, investigating the kinematic relationship between the upper extremity and core muscles may provide a better understanding of motor control in PwMS.

\section{REFERENCES}

[1] Kister I, Bacon TE, Chamot E, Salter AR, Cutter GR, Kalina JT, Herbert J. Natural history of multiple sclerosis symptoms. Int J MS Care 2013;15(3):146-156.

[2] Yozbatıran N, Baskurt F, Baskurt Z, Ozakbas S, Idiman E. Motor assessment of upper extremity function and its relation with fatigue, cognitive function and quality of life in multiple sclerosis patients. J Neurol Sci 2006;246(1-2):117-122.

[3] Rosenblum S, Josman N. The relationship between postural control and fine manual dexterity. Phys Occup Ther Pediatr 2003;23(4):47-60.

[4] Kibler WB, Press J, Sciascia A. The role of core stability in athletic function. Sports Med 2006;36(3):189-198.

[5] Shinkle J, Nesser TW, Demchak TJ, McMannus DM. Effect of core strength on the measure of power in the extremities. J Strength Cond Res 2012;26(2):373-380.

[6] Willson JD, Dougherty CP, Ireland ML, Davis IM. Core stability and its relationship to lower extremity function and injury. J Am Acad Orthop Surg 2005;13(5):316-325.

[7] Bergmark A. Stability of the lumbar spine: a study in mechanical engineering. Acta Orthop Scand 1989;60(sup230):1-54.

[8] Fry DK, Huang M, Rodda BJ. Core muscle strength and endurance measures in ambulatory persons with multiple sclerosis: validity and reliability. Int J Rehabil Res 2015;38(3):206-212. 
[9] Peate W, Bates G, Lunda K, Francis S, Bellamy K. Core strength: a new model for injury prediction and prevention. J Occup Med Toxicol 2007;2(1):3.

[10] Flatters I, Mushtaq F, Hill LJ, Holt RJ, Wilkie RM, Mon-Williams M. The relationship between a child's postural stability and manual dexterity. Exp Brain Res 2014;232(9):2907-2917.

[11] Kalkan AC, Kahraman T, Ugut BO, Colakoglu BD, Genc A. A comparison of the relationship between manual dexterity and postural control in young and older individuals with Parkinson's disease. J Clin Neurosci 2020;75:89-93.

[12] Soke F, Kul Karaali H, llgin D, Yuksel E, Ozcan O, Arslan T. Relationship between Postural Control and Hand Function in the Subjects Aged 65 Years and Over. Turk J Physiother Rehabil 2018;29(1):33-38.

[13] Cetisli Korkmaz N, Can Akman T, Kilavuz Oren G, Bir LS. Trunk control: The essence for upper limb functionality in patients with multiple sclerosis. Mult Scler Relat Disord 2018;24:101106.

[14] Thompson AJ, Banwell BL, Barkhof F, Carroll WM, Coetzee T, Comi G, Correale J, Fazekas F, Filippi M, Freedman MS, Fujihara K, Galetta SL, Hartung HP, Kappos L, Lublin FD, Marrie RA, Miller AE, Miller DH, Montalban X, Mowry EM, Sorensen PS, Tintoré M, Traboulsee AL, Trojano, Uitdehaag BMJ, Vukusic S, Waubant E, Weinshenker BG, Reingold SC, Cohen JA. Diagnosis of multiple sclerosis: 2017 revisions of the McDonald criteria. Lancet Neurol 2018;17(2):162-173.

[15] Kurtzke JF. Rating neurologic impairment in multiple sclerosis: an expanded disability status scale (EDSS). Neurology 1983;33(11):1444-1452.

[16] Feys P, Lamers I, Francis G, Benedict R, Phillips G, LaRocca N, Hudson LD, Rudick R, Consortium MSOA. The Nine-Hole Peg Test as a manual dexterity performance measure for multiple sclerosis. Mult Scler 2017;23(5):711-720.

[17] Mathiowetz V, Weber K, Kashman N, Volland G. Adult norms for the nine hole peg test of finger dexterity. Am J Occup Ther 1985;5(1):24-38.

[18] McGill SM. Low back stability: from formal description to issues for performance and rehabilitation. Exerc Sport Sci Rev 2001;29(1):26-31.

[19] Evans K, Refshauge KM, Adams R. Trunk muscle endurance tests: reliability, and gender differences in athletes. J Sci Med Sport 2007;10(6):447-455.

[20] McGill SM, Childs A, Liebenson C. Endurance times for low back stabilization exercises: clinical targets for testing and training from a normal database. Arch Phys Med Rehabil 1999;80(8):941-944.
[21] Schober P, Boer C, Schwarte LA. Correlation coefficients: appropriate use and interpretation. Anesth Analg 2018;126(5):1763-1768.

[22] Cutter GR, Baier ML, Rudick RA, Cookfair DL, Fischer JS, Petkau J, Syndulko K, Weinshenker BG, Antel JP, Confavreux C. Development of a multiple sclerosis functional composite as a clinical trial outcome measure. Brain 1999;122(5):871-882.

[23] Lamers I, Kelchtermans S, Baert I, Feys P. Upper limb assessment in multiple sclerosis: a systematic review of outcome measures and their psychometric properties. Arch Phys Med Rehabil 2014;95(6):1184-1200.

[24] Bertoni R, Lamers I, Chen CC, Feys P, Cattaneo D. Unilateral and bilateral upper limb dysfunction at body functions, activity and participation levels in people with multiple sclerosis. Mult Scler 2015;21(12):1566-1574.

[25] Hodges PW. Core stability exercise in chronic low back pain. Orthop Clin North Am 2003;34(2):245-254.

[26] Freund JE, Stetts DM, Vallabhajosula S. Relationships between trunk performance, gait and postural control in persons with multiple sclerosis. NeuroRehabilitation 2016;39(2):305-317.

[27] Kocahan T, Akinoglu B. Determination of the relationship between core endurance and isokinetic muscle strength of elite athletes. J Exerc Rehabil 2018;14(3):413-418.

[28] Lehman GJ, Story S, Mabee R. Influence of static lumbar flexion on the trunk muscles' response to sudden arm movements. Chiropr Osteopat 2005;13(1):13-23.

[29] Saeterbakken AH, Van den Tillaar R, Seiler S. Effect of core stability training on throwing velocity in female handball players. J Strength Cond Res 2011;25(3):712-718.

[30] Misirlioglu TO, Eren I, Canbulat N, Cobanoglu E, Gunerbuyuk C, Demirhan M. Does a core stabilization exercise program have a role on shoulder rehabilitation? A comparative study in young females. Turk J Phys Med Rehabil 2018;64(4):328-336.

[31] Miyake Y, Kobayashi R, Kelepecz D, Nakajima M. Core exercises elevate trunk stability to facilitate skilled motor behavior of the upper extremities. J Bodyw Mov Ther 2013;17(2):259-265.

[32] Bulguroglu I, Guclu-Gunduz A, Yazici G, Ozkul C, Irkec C, Nazliel B, Batur-Caglayan H. The effects of Mat Pilates and Reformer Pilates in patients with Multiple Sclerosis: A randomized controlled study. NeuroRehabilitation 2017;41(2):413-422.

[33] Freeman JA, Gear M, Pauli A, Cowan P, Finnigan C, Hunter $H$, Mobberley C, Nock A, Sims R, Thain J. The effect of core stability training on balance and mobility in ambulant individuals with multiple sclerosis: a multi-centre series of single case studies. Mult Scler 2010;16(11):1377-1384.

How to cite this article: Ozkul C, Guclu Gunduz A, Esmer M, Yildirim MS, Eldemir K, Irkec C. Mutual Relationship Between Upper Extremity Function and Core Muscle Endurance in Patients with Multiple Sclerosis. Clin Exp Health Sci 2021; 11: 42-46. DOI: 10.33808/clinexphealthsci.809605 